\title{
Alterações dos biomarcadores em equinos Mangalarga Marchador com a obesidade induzida
}

Rodrigo Martins Ribeiro", Debora da Silva Freitas Ribeiro, Cahue Francisco Rosa Paz, Davi Silveira Diniz Azevedo, Leticia Oliveira Cota, Antônio Catunda Pinho Neto, Rafael Resende Faleiros

*Autor correspondente

e-mail: vetrodrigo@msn.com

\section{Resumo}

A Síndrome Metabólica Equina (SME) se caracteriza por um distúrbio metabólico associado à obesidade, que predispõe os cavalos à laminite endocrinopática. 0 objetivo deste experimento foi caracterizar as alterações no perfil hormonal e metabólico de equinos Mangalarga Marchador (MM) submetidos à dieta hipercalórica, com a finalidade de verificar e conhecer melhor o desenvolvimento da síndrome metabólica equina e tentar encontrar ferramentas que possibilitem a realização de seu diagnóstico precoce. Foram utilizados 9 equinos adultos MM com escore corporal (EC) médio $( \pm \mathrm{DP}$ ) inicial de 2,9 \pm 1 (escala de 1 - 9) submetidos à dieta hipercalórica atingido um EC de 8,3 \pm 1 após 5 meses. Os dados foram coletados antes do início do experimento e com intervalo de 15 dias até o final do experimento. Os valores plasmáticos foram obtidos para mensuração das concentrações de HDL-c, LDL-c, VLDL-c, ácidos graxos não esterificados (AGNE), frutosamina, glicose, colesterol total, triglicérides e insulina. Os resultados foram submetidos à análise de variância, considerandose os efeitos de tempo, e as médias comparadas com medidas repetidas pelo teste de Tukey, com o valor $\mathrm{P}$ $\leq 0,05$. A dieta hipercalórica promoveu importante impacto no metabolismo dos equinos estudados com aumento nas concentrações sanguíneas já nos primeiros 30 dias de experimento de colesterol total $(P \leq 0,05)$, LDL-c ( $\mathrm{P} \leq 0,001)$, HDL-c $(\mathrm{P} \leq 0,001)$ e insulina plasmática $(\mathrm{P} \leq 0,001)$. Tais achados comprovam a ocorrência de hiperinsulinemia e hipercolesterolemia em equinos MM expostos à dieta hipercalórica.

Palavras-chave: Síndrome metabólica equina. Cavalo. Dieta hipercalórica. 